\title{
Checklist of the First Recorded Spider Fauna in Sheringal, Khyber Pakhtunkhwa, Pakistan*
}

\author{
Farzana Perveen\#, Numan Khan \\ Department of Zoology, Shaheed Benazir Bhutto University (SBBU), Main Campus, Sheringal, \\ Khyber Pakhtunkhwa (KP), Pakistan \\ Email: "farzana san@hotmail.com
}

Received 23 April 2015; accepted 15 June 2015; published 18 June 2015

Copyright $@ 2015$ by authors and Scientific Research Publishing Inc.

This work is licensed under the Creative Commons Attribution International License (CC BY). http://creativecommons.org/licenses/by/4.0/

\section{Abstract}

The spiders are the member of the class Arachnida of the phylum Arthropoda with a hard cephalothorax and soft abdomen. They are environmental indicators and play an important role in biological control of insect population. The present study was conducted to prepare the checklist of the first recorded spider fauna of the 6 quadrates, i.e., Daramdala, Doki, Guryaal, Samang, Shahoor and Sia-Sheringal of Sheringal, Dir Upper (DU), Khyber Pakhtunkhwa (KP), Pakistan during June 2013-July 2014. Ten species (spp) belonging to 7 families, and 10 genera $(n=123$ : total; $n=77$ : identified; $n=46$ : unidentified) were recorded. The family Opilionidae ( $n=12)$ : harvestmen spider, Hadrobunus grandis Sundevall, 1833; family, Hersiliidae $(n=6)$ : two-tailed spider, Harsilia savignyi Lucas, 1836; family, Pholcidae $(\mathrm{n}=10$ ): cellar spider, Crossopriza lyoni Blackwall, 1867; family, Araneidae ( $n=5$ ): garden spider, Araneus diadematus Clerck, 1757; family, Gnaphosidae (n = 3): ground spider, Gnaphosa eucalyptus Ghafoor and Beg, 2002 were with one species; family, Sparassidae ( $=19$ ), huntsman spider with $2 \mathrm{spp}$ including Halconia insignis Thorell, 1836, and Isopeda tuhogniga Barrion and Litsinger, 1995; while the highest number of species caught from family Lycosidae $(n=20)$ : wolf spider with 3 spp including Arctosa littorali Simon, 1897; Hippasa partita Takidar, 1970 and Pardosa distincta Backwall, 1867 were recorded. It was concluded that 7 families with 10 genera and species each, respectively, were identified from the study area. A detail study is required for further enhancing of the biodiversity of the spider fauna of Sheringal, KP, Pakistan for synthesis of the ethnozoopharmaco-products.

\footnotetext{
*The research work has been conducted in Department of Zoology, Shaheed Benazir Bhutto University (SBBU), Main Campus, Sheringal, Khyber Pakhtunkhwa (KP), Pakistan.

"Corresponding author.
} 


\section{Keywords}

\section{Arachnida, Cephalothorax, Lycosidae, Sparassidae, Spider Fauna}

\section{Introduction}

The class Arachnida, in the phylum Arthropoda, contains spiders, which are considered as the dreadful organisms. However, they have 2 body parts, i.e., a cephalothorax and an abdomen. When head and thorax united together to form cephalothoraxes, which is hard part of the body with 4 pairs of legs and other appendages, which are used for movement of body and searching for food. Moreover, the abdomen is soft and unsegmented with reproductive appendages. Furthermore, they are mostly carnivorous, typically, they prey on insects and other terrestrial organisms. They keep insects/pests populations under control by providing an important service, i.e., they act as biological control agents [1].

The spider diversity, distribution, and feeding habits are the factors, which believed to play an important role in balancing of nature [2]. They are the most abundant invertebrate that have imposed the greatest threat on insect species [3] [4]. Ferguson et al. [5] reported that they protect the crops from significant pests. They are predators of herbivorous insects as well as capable of reducing small invertebrates population that may not be limited by competition and food availability in some agro-ecosystems. Several studies have shown that insect populations significantly increase, when they escape from predation by spiders [6].

The fact about the origin of spiders is doubtful. According to many scientists, they originated in the sea. They evolved in 2 groups, i.e., with and without extensor leg muscles. The spiders evolved around 400 million years ago. The earliest spiders were larger and more segmented as compare to the recent one. The sub-order Mesotherae is considering the ancient type of spiders [7].

They contain spinneret glands, found at the tip of their abdomen. However, their numbers are different, may be 1 - 4 pairs, moreover, their function is to produce silk. Further, the silk is a thread, which is produced by each gland for a special purpose, e.g., a trail silk for safety line, fine for wrapping, and sticky for capturing prey. There are up to 8 different types of silk may be produced. Females' spiders are larger than males and the epigynum is the female reproductive organ, situated on the ventral side of the abdomen. The trachea and book lungs are breathing organs [8]. They are varying in size and colors. The giant bird-eating spider, of the family Theraphosidae (Thorell), size is $75 \mathrm{~mm}$ with leg-length up to $255 \mathrm{~mm}$. Their metamorphosis takes place through molting, in which their sizes increase with the replacement of hard and old skin with new one [9].

Sheringal valley is located between $720^{\circ}-200^{\circ}$ east longitudes and $350^{\circ}-280^{\circ}$ north latitude in Pakistan. Altitude is approximately $2000 \mathrm{~m}$ above the sea level. This is a small valley situated northern site of district Dir Upper (DU), Khyber Pakhtunkhwa (KP), Pakistan. Bajauar Agency and Jandool is located toward the west, while it is surrounded by district Swat and Malakand Agency from the East and South, respectively. Total area covered by this hilly valley is 7992.67 hectares. The Northern part is generally covered with green-lush forests. The river Panjkora flows towards the north-south. The climate is very cold in the winter and warm in the summer which is very short. The minimum and maximum temperature in January has been recorded as -2.3 and $11.22^{\circ} \mathrm{C}$, respectively (Figure 1). In Sheringal, a number of wildlife fauna including mammals such as snow leopard, Panthera uncia (Schereber, 1775); common leopard, Panthera pardus (L, 1758); musk deer, Moschus anhuicnsis (L, 1758) etc. The Himalayan monal pheasant, Lophophorus impejanus (Latham, 1790); Himalayan snow cock, Tetraoggallus himalayensis (Gray, 1848) and snow partridge, Lerwa lerwa (Hodgson, 1837) are some of the key bird species found here [10]. The objective of the present research is to prepare the checklist of the first recorded spider fauna and to educate the people of Sheringal about them (Figure 1).

\section{Materials and Methods}

The current research was conducted during June 2013-August 2014 in 6 quadrates, i.e., Daramdala, Doki, Guryaal, Samang, Shahoor and Sia Sheringal of the study area, Sheringal, Dir Upper (DU), Khyber Pakhtunkhwa (KP), Pakistan (Figure 1). The people of Sheringal usually depend upon agriculture for livelihood. The total area covered by this hilly valley is 7992.7 acres. The population is about 20,000 and literacy rate is $51 \%$.

For the collection of spiders, the bottles were distributed randomly in community of quadrates of the study area. The procedure of collection of the spiders has been explained. The author and volunteer-children were the 


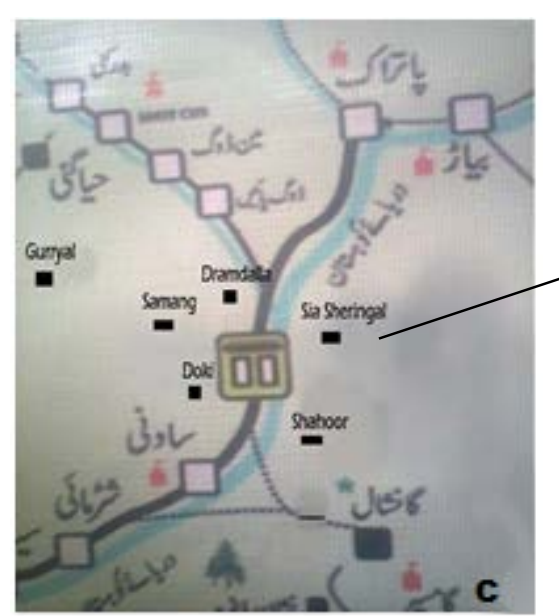

(a)

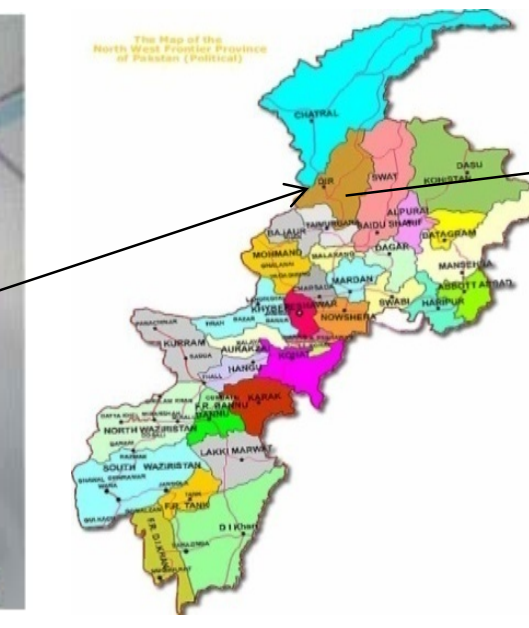

(b)

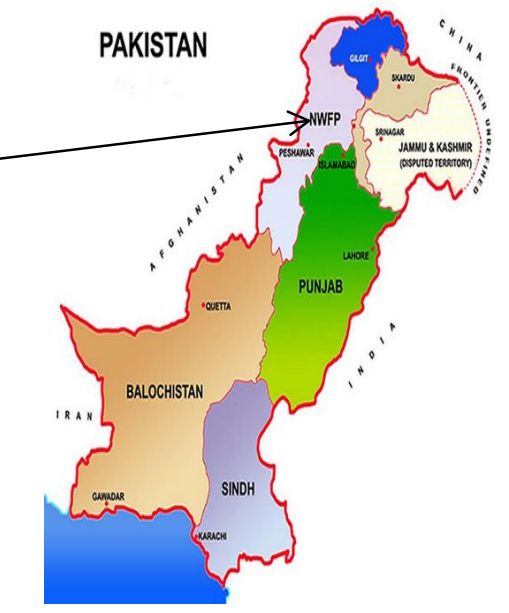

(c)

Figure 1. Study area from where the checklist of the first recorded spider fauna has been prepared, i.e., Sheringal, Dir Upper, Khyber Pakhtunkhwa, Pakistan from June 2013-August 2014: arrows show map of 6 quadrates of study area, viz., Daramdala, Doki, Guryaal, Samang, Shahoor and Sia Sheringal are located in Sheringal (a), where the present research was conducted, it is located in the Khyber Pakhtunkhwa (b), which is one of the provinces of Pakistan (c) [11].

individuals who collected the spiders through various methods like pitfall method [4] and simply by hands picking etc. The spider collected were brought to the laboratory, Department of Zoology (DOZ), Shaheed Benazir Bhutto University (SBBU), Sheringal, DU, KP, Pakistan and faint by mortin ${ }^{\circledR}$ (CIC Enterpriser, Lahore, Pakis$\tan$ ) in the Jars. Then they were identified with the help of keys [12] [13], literature available, preserved specimens and also identified through internet. The specimens were labeled and preserved in $70 \%$ ethanol with few drops of glycerin. They were deposited in Natural History Museum, Department of Zoology, Shaheed Benazir Bhutto University.

\section{Results}

The spider fauna at Sheringal was 1st time recorded. The most specimens collected were belonging to wolfspiders $(n=20)$ and few belong to long tailed-spiders $(n=6)$. Total 120 specimens has been collected, however, due to unavoidable circumstances 43 specimen has been unidetified, moreover, 77 specimens were identified to species level, they belong to 7 families. The most dominant family among spider species collected was Lycosidae. However, the less number of species were recorded from families Gnphosidae, Araneidae and Hersiliidae. These 10 species were The harvestmen spider, Hadrobunus grandis Sundevall, 1833 (Family: Opilionidae; $\mathrm{n}=$ 12); two-tailed spider, Harsilia savignyi Lucas, 1836 (Family: Hersiliidae; $\mathrm{n}=6$ ); cellar spider, Crossopriza lyoni Blackwall, 1867 (Family: Pholcidae; $\mathrm{n}=10$ ); garden spider, Araneus diadematus Clerck, 1757(Family: Araneidae; n = 5); ground spider, Gnaphosa eucalyptus Ghafoor and Beg, 2002 (Family: Gnaphosidae; n = 3); huntsman spiders with 2 spp including Halconia insignis Thorell, 1836 and Isopeda tuhogniga Barrion and Litsinger, 1995 (Family: Sparassidae; $\mathrm{n}=19$ ); and wolf spider with 3 spp including Arctosa littorali Simon, 1897; Hippasa partita Takidar, 1970 and Pardosa distincta Backwall, 1867 (Family: Lycosidae; $\mathrm{n}=20$ ). The checklist of the spider fauna in Sheringal, DU, KP, Pakistan is prepared, and presented in Table 1:

Kingdom: Animalia

Phylum: Arthropoda

Sub-Phylum: Chelicerate

Class: Arachnida

Order: Aranae

Suborder: Araneomorphae

I) Family: Araneidae

Reported species 1: Garden spider, Araneus diadematus Clerck, 1757

II) Family: Gnphosidae

Reported species 2: Ground spider, Gnaphosa eucalyptus Ghafoor and Beg, 2002 
Table 1. Checklist of spider fauna collected from the study area, Sheringal, Dir Upper, Khyber Pakhtunkhwa, Pakistan during June 2013-August 2014.

\begin{tabular}{cccccccccc}
\hline SNo & Family & Common name & Scientific name & Authority & Year & $\mathbf{n}^{*}$ & Status & Date & Place \\
\hline 1 & Araneidae & Garden spider & Araneusdia dematus & Clerck & 1757 & 5 & $\mathrm{R}^{*}$ & $20 / 7 / 2013$ & $\mathrm{q}^{3}$ \\
2 & Gnphosidae & Ground-spider & Gnaphosa eucalyptus & Ghafoor and Beg & 2002 & 3 & $\mathrm{R}^{*}$ & $27 / 8 / 2013$ & $\mathrm{q}^{6}$ \\
3 & Hersiliidae & Two-tailed spider & Harsilia savignyi & Lucas & 1836 & 6 & $\mathrm{R}^{*}$ & $28 / 9 / 2013$ & $\mathrm{q}^{5}$ \\
& & & Arctosa littorali & Simon & 1897 & 8 & $\mathrm{~F}^{*}$ & $29 / 10 / 013$ & $\mathrm{q}^{1}$ \\
4 & Lycosidae & Wolf spider & Hippasa partita & Takidar & 1970 & 6 & $\mathrm{~F}^{*}$ & $27 / 11 / 013$ & $\mathrm{q}^{1}$ \\
& & & Pardosa distincta & Backwall & 1867 & 6 & $\mathrm{~F}^{*}$ & $7 / 4 / 2014$ & $\mathrm{q}^{1}$ \\
5 & Opilionidae & Harvestmen spider & Hadrobunus grandis & Sundevall & 1833 & 12 & $\mathrm{C}^{*}$ & $9 / 5 / 2014$ & $\mathrm{q}^{2}$ \\
6 & Pholcidae & Cellar spider & Crossopriza lyoni & Blackwall & 1867 & 10 & $\mathrm{C}^{*}$ & $8 / 6 / 2014$ & $\mathrm{q}^{2}$ \\
& & & Halconia insignis & Thorell & 1836 & 9 & $\mathrm{~F}^{*}$ & $10 / 7 / 2014$ & $\mathrm{q}^{4}$ \\
\hline
\end{tabular}

*F: Frequent; C: common; R: Rare; n: number of specimens collected; $q^{1}$ : Sia Sheringal; $q^{2}$ : Doki; $q^{3}$ : Shahoor; $q^{4}$ : Samang; $q^{5}$ : Dramdala; $q^{6}$ : Guryal.

III) Family: Hersiliidae

Reported species 3: Two-tailed spiders, Harsilia savignyi Lucas, 1836

IV) Family: Lycosidae

Reported species 4: Wolf spider, Arctosa littorali Simon, 1897

5: Hippasa partita Takidar, 1970

6: Pardosa distincta Backwall, 1867

Suborder: Eupnoi

V) Family: Opilionidae

Subfamily: Phalangioidea

Reported species 7: Harvestmen spider, Hadrobunus grandis Sundevall, 1833

VI) Family: Pholcidae

Reported species 8: Cellar spider, Crossopriza lyoni Blackwall, 1867

VII) Family: Sparassidae

Reported species 9: Huntsman spiders, Halconia insignis Thorell, 1836

10: Isopeda tuhogniga Barrion and Litsinger, 1995

The morphometric measurements of the different parts of the spiders such as cephalothorax, abdomen and total body size were conducted. It was found that $H$. partita (Family: Lycosidae) was the largest spider with the largest both cephalothorax and abdomen. However, H. savignyi (Family: Hersiliidae) and C. lyoni (Family: Pholcidae) were the smallest spiders with the smallest both cephalothorax and abdomen (Table 2).

\section{Discussion}

In this study, collection and identification of the first recorded spiders of Sheringal, DU, KP, Pakistan was conducted from June 2013-August 2014 in which, 10 species distributed in 10 genera and 7 families.

Arshed et al. [14] reported 18 species in 13 genera and 8 families of the spiders in Peshawar. However, Tahir and Butt [15] reported on the biodiversity and predatory efficacy of the spiders in rice field in central Punjab, Pakistan, and 44 species of spider were recorded from 28,000 specimens of spiders. Moreover, Mukhtar [16] surveyed the spider fauna of the foliage from Punjab and reported 124 species belonging to 51 genera and 17 families with the most dominant family was Araneidae, while the less abundant species was from Corinnedae family. Furthermore, Ursani and Soomro [17] updated the checklist of spider fauna from 16 districts of Sindh, province, Pakistan. A total of 132 species were recorded belonging to 24 families and 73 genera. Majority of these species were earlier defined, however, only family Zodariidae for the first time was recorded from Pakistan. Furthermore, Namkung et al. [13] reported a critical checklist of the spiders from Jeju Island, Korea with 
Table 2. Morphometric measurements of the first recorded spider fauna collected from the study area, Sheringal, Dir Upper, Khyber Pakhtunkhwa, Pakistan during June 2013-August 2014.

\begin{tabular}{|c|c|c|c|c|c|c|c|}
\hline \multirow{2}{*}{ SNo } & \multirow{2}{*}{ Family } & \multirow{2}{*}{ Common name } & \multirow{2}{*}{ Scientific name } & \multirow{2}{*}{$\mathbf{n}^{*}$} & Cephalothorax & Abdomen & Total body \\
\hline & & & & & \multicolumn{3}{|c|}{$\mathrm{M} \pm \mathrm{SD}(\mathrm{cm})$} \\
\hline 1 & Araneidae & Garden spider & Araneusdia dematus & 5 & $0.2 \pm 0.04$ & $0.3 \pm 0.04$ & $0.64 \pm 0.08$ \\
\hline 2 & Gnphosidae & Ground-spider & Gnaphosa eucalyptus & 3 & $0.2 \pm 0.08$ & $0.3 \pm 0$ & $0.5 \pm 0.08$ \\
\hline \multirow[t]{2}{*}{3} & Hersiliidae & Two-tailed spider & Harsilia savignyi & 6 & $0.1 \pm 0.04$ & $0.2 \pm 0.4$ & $0.3 \pm 0.04$ \\
\hline & & & Arctosa littorali & 8 & $0.25 \pm 0.05$ & $0.35 \pm 0.1$ & $0.6 \pm 0.15$ \\
\hline \multirow[t]{2}{*}{4} & Lycosidae & Wolf spider & Hippasa partita & 6 & $1.1 \pm 0.01$ & $0.7 \pm 0.1$ & $1.8 \pm 02$ \\
\hline & & & Pardosa distincta & 6 & $0.2 \pm 0.03$ & $0.3 \pm 0.05$ & $0.56 \pm 0.07$ \\
\hline 5 & Opilionidae & Harvestmen spider & Hadrobunus grandis & 12 & $0.1 \pm 0.04$ & $0.3 \pm 0.04$ & $0.45 \pm 0.09$ \\
\hline 6 & Pholcidae & Cellar spider & Crossopriza lyoni & 10 & $0.1 \pm 0$ & $0.2 \pm 0.04$ & $0.41 \pm 0.15$ \\
\hline \multirow{2}{*}{7} & Snorncidno & Huntcmonschidor & Halconia insignis & 9 & $0.3 \pm 0.04$ & $0.36 \pm 0.04$ & $0.7 \pm 0.09$ \\
\hline & & & Isopeda tuhogniga & 10 & $0.3 \pm 0.08$ & $0.37 \pm 0.07$ & $0.67 \pm 0.16$ \\
\hline
\end{tabular}

${ }^{*} \mathrm{n}$ : number of specimens measured; $\mathrm{M} \pm \mathrm{SD}$ : mean \pm standard deviation; $0 \pm 0$ : cephalothorax almost absent.

review of published reports during 1936-2001 and identified specimens collected from 1964-2001. Total of 166 genera and 347 species belonging to 36 families of spiders were classified from Jeju Island [13]. Although, Sebata [18] reported that spiders were collected during 10 weekly sessions, in which 663 individuals in 28 species were distributed among the 11 families found in the Hillside Dams Conservancy, Bulawayo, Zimbabwe. Therefore, during the present research, total of 123 individuals belonging to 10 species distributed among 7 families were found, in which 77 were identified from 6 quadrates of Sheringal, i.e., Daramdala, Doki, Guryaal, Samang, Shahoor and, sia sheringal, where the largest family was Lycosidae with 3 species, while the smallest families were Opilionidae, Hersiliidae, Araneidae, and Gnphosidae each with only one species. The above mentioned studies showed difference in the climatic factors, geographical occurrence, temperature and weather etc. However, the area of study was more toward the northern pole and away from equator and the climatic conditions were little colder than others. Presently, the period for the collection of spiders was the shortest (5) weeks as compared to researches given above. Therefore, number of specimens collected was small.

The abundance of spiders in the vegetative habitats in Southwestern Nigeria depended greatly upon the availability of prey which serves as food for the spider, thus a spider population often reflected the number of preys in the given area [19]. Whitmore et al. [20] reported that high number of spiders' families were recorded in cultivated and open field habitats and reflected vegetation complexity which spider relied on their life cycle, either for finding food, building retreats or for web building. The structure of the vegetation has been reported to influence the diversity of spider fauna in the habitat with complex vegetation. During the present research, the abundance of the spider fauna were recorded from inside the buildings, close houses, old shops, roads, garden, field and in crevices of the trees due to the availability of their preys as insects are the main source of food for spiders, thus were observed abundance in the warm and hidden areas, the habitats of spiders during this research were diverse, and related to the availability of the insects prey.

In this study, the majority of the spiders were collected from shops, buildings and in crevices of the trees. The largest spider encounter being the family Sparassidae has the first leg length of $1.9 \pm 0.20$, while the fourth leg length was $1.44 \pm 0.25$. However, the smallest spider was of Gnaphosa from the family Gnaphosidae, whose the first leg length is $0.4 \pm 0.08$, while the fourth leg length was $0.4 \pm 0.08$ was recorded. It was observed that $50 \%$ of the species were allergenic and injurious in Sheringal. As it is the colder area of Pakistan, therefore, their breeding season was short than other warmer areas.

There were many limitations for the current work including shortage of time for research and unavailability of funding etc. However, the summer season, in which the insects' population found abundantly, was very short in Sheringal, which also affected the collection of spiders. Moreover, there were many limitations related to people of community, such as they are poor with very low literacy rate. Additionally, there was low standard of living 
and feeding habits, unhygienic way of living and low values of ethical norms. Further, they unaware of spiders and consider them horrible organisms. Therefore, when spiders were collected, most of the spiders were damaged and legs were lost completely. Furthermore, geographical distribution of the study area was also a big hurdle for the collection of spiders due to high mountains and rocks with frequent land-sliding. In addition, weather with heavy rain and snow fall were also created problems in collection. Besides, there was unavailability of facilities of research etc. As well as the chemicals and equipments for collection of the spiders were not satisfactory.

\section{Conclusion}

In this study, a total of 123 spider specimens were collected, out of which 77 specimens were identified to genus and species levels, with the species least number is Gnaphosidae $(n=3)$, while species with the highest number is Lycosidae $(n=20)$.

\section{Recommendation}

It is recommended that further research, a detailed study is required to identify new species in the area. The details needed is on the production of silk and web formation. Pre-classes, seminars, symposium and workshops may be arranged for better research in future and awareness of the people's ethono-zoology.

\section{Acknowledgements}

Authors are grateful to all the people assisted in conducting this survey. We would like to thanks Mr. Inayat Ul Islam, a classmate, for his kind suggestions and cooperation in data analysis. The present research complies with the current laws of the institute and country, in which they were performed.

\section{References}

[1] Marc, P., Canard, A. and Ysnel, F. (1999) Spiders (Araneae) Useful for Pest Limitation and Bio-Indication. Agriculture, Ecosystems and Environment, 74, 229-273. http://dx.doi.org/10.1016/S0167-8809(99)00038-9

[2] Young, O.P. and Edwards, G.B. (1990) Spiders in United States Field Crops and Their Potential Effect on Crop Pests. Journal of Arachnology, 18, 1-27.

[3] Marc, P. and Canard, A. (1997) Maintaining Spider Biodiversity in Agro-Ecosystems as a Tool in Pest Control. Agriculture, Ecosystems \& Environment, 62, 229-235. http://dx.doi.org/10.1016/S0167-8809(96)01133-4

[4] Gill, H.K., McSorley, R. and Buss. L. (2010) The Insect Community on the Soil Surface. http://edis.ifas.ufl.edu/in876

[5] Ferguson, H.J, Mcpherson, R.M. and Allen, W.A. (1984) Ground and Foliage-Dwelling Spiders in Four Soybean Cropping Systems. Environmental Entomology, 13, 975-980. http://dx.doi.org/10.1093/ee/13.4.975

[6] Sunderland, K.D. (1999) Mechanisms Underlying the Effects of Spiders on Pest Populations. Journal of Arachnology, 27, 308-316.

[7] Karren, J.B. (2002) Spiders. Utah University, Salt Lake City, 22-34.

[8] Nieuwenhuys, A. (2008) Spider Information. http://ednieuw.home.xs4all.nl/Spiders

[9] Kingsley, R. (1999) The Spiders. New Star Standard Industries (Pvt) Ltd., Singapore, 1-34.

[10] Hazrat, A., Shah, J. and Nisar, M. (2011) Medicinal plants of Sheringal Valley, Dir Upper, KPK, Pakistan. Fuuast Journal of Biology, 1, 131-133.

[11] Online Maps (2013) www.google.com

[12] Levi, H.W. Randolph, D.E. (1975) A Key and Checklist of American Spiders of the Family Theridiidae North of Mexico (Araneae). Journal of Arachnology, 3, 31-51.

[13] Namkung, J., Im, M.S., Kim, S.T. and Lee, J.H. (2002) Spider Fauna of Jeju Island in Korea. Journal Asia-Pacific Entomology, 5, 55-74. http://dx.doi.org/10.1016/S1226-8615(08)60133-8

[14] Arshad, M., Jan G.A. and Iqbal, M. (1984) Some Spiders of Peshawar and Adjoining Areas. Zoological Survey of Pakistan, 10, 83-89.

[15] Tahir, M. and Butt, A. (2009) Some New Species of Family Lycosidae from Agricultural Fields of Punjab, Pakistan. Pakistan Journal of Zoology, 38, 185-189.

[16] Mukhtar, M.K. (2004) Taxonomic studies on the foliage Spider Fauna of Punjab. Department of Zoology and Fisheries, 
University of Agriculture, Faisalabad, 1-76.

[17] Ursani, T.J. and Soomro, N.M. (2010) Checklist of Spider Fauna of Sindh Province, Pakistan. Pakistan Journal of Entomology, Karachi, Pakistan, 32, 61-73.

[18] Sebata, S. (2015) Species Composition and Abundance of the Spider Fauna of the Hillside Dams Conservancy, Bulawayo, Zimbabwe. Researcher, 7, 44-49.

[19] Turnbull, A.C. (1973) Ecology of the True Spiders (Araneomorphae). Annual Review of Entomology, 18, $305-358$. http://dx.doi.org/10.1146/annurev.en.18.010173.001513

[20] Whitmore, C., Slotow, R., Crouch, T.E. and Dippenaar-Schoeman, A.S. (2002) Diversity of Spiders (Araneae) in a Savanna Reserve, Northern Province, South Africa. Journal of Arachnology, 30, 344-356.

http://dx.doi.org/10.1636/0161-8202(2002)030[0344:DOSAIA]2.0.CO;2 